Indonesian Journal of Physics

Vol 19 No. 1, January 2008

\title{
Study on Void Reactivity of Liquid Metal Fast Breeder Reactor
}

\author{
Azizul Khakim, T. Yokoyama, andHisashi Ninokata \\ Research Laboratory for Nuclear Reactors \\ Tokyo Institute of Technology, O-okayama, Meguro-Ku, Tokyo 152-8550 Japan \\ e-mail:06m19216@nr.titech.ac.jp
}

\begin{abstract}
Liquid Metal Fast Breeder Reactor (LMFBR) usually has positive void reactivity which is not favorable to the reactor safety. Therefore, the void generation should be avoided during normal reactor operation. Design of reactor core should consider the parameters that influence the void reactivity in order to minimize it, should void be generated during an accident. In this study, several parameters have been evaluated to observe their contribution to the overall void reactivity, such as the build-up of minor actinides (MAs), different inner and outer core height, heterogeneous core configuration, upper plenum, upper axial blanket, voiding in the inner and outer core and the effect of P/D. The study is performed in 3-D heterogeneous geometry using Monte Carlo Method of MVP Code with JENDL-3.3
\end{abstract}

Keywords : LMFBR, minor actinides, 3-D heterogeneous geometry, MVP Code

\section{Introduction}

Even though in LMFBR, void is not allowed to occur during normal operation, but it could appear during an accident. Since void generation tends to induce positive reactivity, it could drastically increase the reactor power that makes the condition even worse and uncontrollable.

During voiding process, the neutron energy spectrum is shifted to higher region (hardening process) due to disappearance of coolant neutron slowing down. Meanwhile, the fission probability of fissile and fissionable materials in the fuel increases as neutron energy increases. Therefore, neutron spectrum hardening contributes positive reactivity.

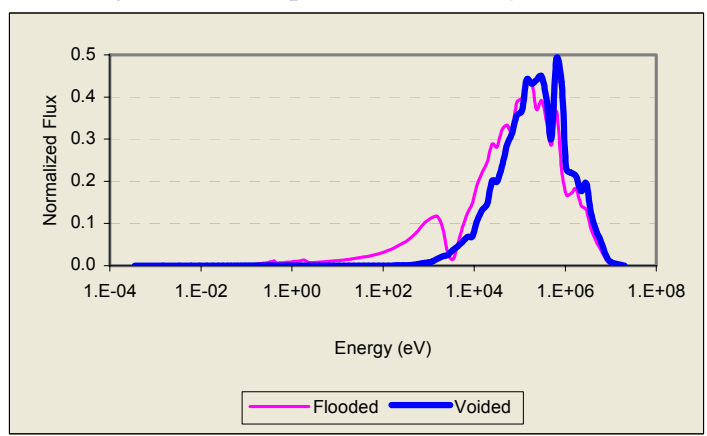

Figure 1. General characteristic of neutron spectrum during flooded and voided condition

On the other hand, the neutron mean free path increases with the absence of coolant or reduction of coolant density that result in increasing neutron leakage. Consequently, the neutron leakage induces negative reactivity that can be employed to compensate the positive reactivity due to the neutron spectrum hardening. The change of coolant capture cross section also limitedly influences on void reactivity.
This study is intended to observe the parameters and design characteristic that affect the void reactivity. Reactor core design should take into account the factors both inducing positive and negative void reactivity to ensure the reactor is reasonably safe during its operational life. They then can be employed to achieve reasonably low positive or even negative void reactivity, if possible.

The calculation is performed using Monte Carlo method of MVP Code with nuclear data JENDL-3.3. The reactor core is modeled in heterogeneous 3-D geometry.

\section{Base Case Core Configuration}

The driver fuel of base case core configuration is mixed of uranium and plutonium oxide (MOX) fuel with $80 \%$ and $20 \%$ of uranium and plutonium, respectively in the heavy metal.

Table1. Reactor specification for base case calculation

\begin{tabular}{|l|r|}
\hline Electrical power, MW & 1000 \\
\hline Thermal power, MW & 2700 \\
\hline CORE PARAMETERS & $0.7 / 1.0$ \\
\hline Inner/outer core height, $\mathrm{m}$ & $9.5 / 11.5$ \\
\hline In/Out Pu fissile enrichment, \% & \\
\hline Fuel/Coolant/Structure, \%vol. & $36.6 / 33.8 / 29.6$ \\
\hline FUEL ASSEMBLY & $150 / 216$ \\
\hline In/Out no. Driver Assembly & $\left(\mathrm{U}_{0.8} \mathrm{Pu}_{0.2}\right) \mathrm{O} 2$ \\
\hline Fuel Type & $\mathrm{He}$ \\
\hline Bond material & 8.5 \\
\hline Pin diameter, mm & $\mathrm{SS}$ \\
\hline Cladding material & 9.8 \\
\hline Pin Pitch, mm & 1.15 \\
\hline P/D & $0.15 / 0.85$ \\
\hline T/B Fission Gas Plenum, $\mathrm{m}$ & 271 \\
\hline No. Pins per Assembly & 173 \\
\hline Duct Flat-to-Flat, mm &
\end{tabular}




\begin{tabular}{|l|r|} 
Duct Thickness, mm & 3 \\
\hline Duct Pitch, mm & 179 \\
\hline Duct material & $\mathrm{SS}$ \\
\hline BLANKET & \\
\hline Material & $\mathrm{UO}_{2}$ \\
\hline Pin Dia., mm & 8.5 \\
\hline Top length, m & 0.3 \\
\hline Bottom length, m & 0.3 \\
\hline No. Radial blanket assemblies & 150 \\
\hline CONTROL & \\
\hline No. Control Assembly & 31 \\
\hline Control and Shielding material & $\mathrm{B}_{4} \mathrm{C}$ \\
\hline
\end{tabular}

In radial direction, the core is divided into four regions, i.e. inner core, outer core having higher enrichment, blanket region and radial shielding material made of boron carbide $\left(\mathrm{B}_{4} \mathrm{C}\right)$. Both radial and axial blanket are made of natural uranium dioxide $\left(\mathrm{UO}_{2}\right)$. The inner core consists of 150 fuel assemblies, while the outer core has 216 driver assemblies. The core is surrounded by 150 blanket assemblies. One fuel assembly consists of 271 fuel pins.

The reactor is controlled by 31 control assemblies made of $\mathrm{B}_{4} \mathrm{C}$ distributed in the inner and outer core. Table 1 shows the reactor specification data for base case calculation.

\section{Void Modeling}

The calculation is performed by assuming that the void is generated by excessive fuel heating during an accident. The voiding regions are also assumed to be completely voided. Therefore, the voiding takes place in the inner and outer core only; it does not occur in the radial blanket nor control assembly positions. In addition, the void is only generated inside the channel box of the fuel assembly, while the space outside the channel box remains flooded, as shown in Figure 2.b.

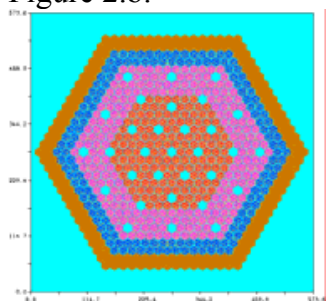

(a)

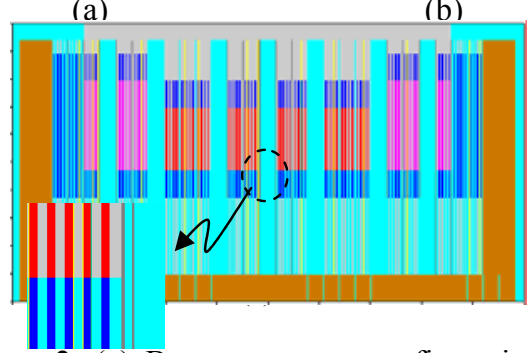

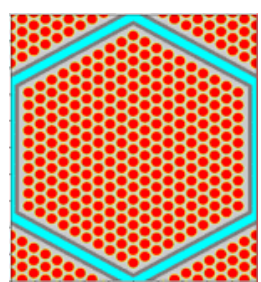

(b)
Figure 2. (a) Base case core configuration, (b) Fuel assembly during voided condition, (c) Axial view during voided
In the axial direction, voiding takes place in the active height of both inner and outer core, and above them. The idea simply comes from the fact that the reactor coolant flows upward. Voiding does not occur in the lower blanket, as it can be seen from Figure 2.c. The space above the inner and outer core is homogeneous mixture of coolant and void. Therefore, the fluid volume fraction above the core is calculated based on total flooded area in the inner and outer core divided by total area of inner and outer core.

\section{Parameters to Be Evaluated}

Base case calculation is performed for homogeneous core configuration as shown in Figure 2, for both flooded and voided condition. The void reactivity is then calculated by reactivity change from flooded to voided condition. The following parameters are to be evaluated to observe their effect on void reactivity.

Case 1: MAs inclusion of $2.26 \%$ of $\mathrm{Pu}$

Case 2: Uniform inner \& outer core height

Case 3: Heterogeneous core configuration

Case 4: Elimination of upper plenum

Case 5: Effect of $85 \mathrm{~cm}$ of upper plenum

Case 6: Shorter upper blanket $(15 \mathrm{~cm})$

Case 7: Voiding in the inner core

Case 8: Voiding in the outer core

Case 9: The effect of pin pitch

\section{Result and Discussion}

\subsection{Base case calculation}

The core configuration for the base case calculation is shown in Fig.2; and Table 1 specifies the detailed reactor data. The $\mathrm{k}_{\mathrm{eff}}$ calculation result during flooded condition is $1.03549 \pm 0.0121 \%$ or 3.427 $\% \Delta \mathrm{k} / \mathrm{k}$ in excess reactivity, while the $\mathrm{k}_{\text {eff }}$ during voided condition is $1.04862 \pm 0.0126 \%$ or 4.637 $\% \Delta \mathrm{k} / \mathrm{k}$. The void reactivity is calculated by the difference of reactivity from flooded to voided condition. Therefore, the void reactivity for the base case calculation is $1.209 \% \Delta \mathrm{k} / \mathrm{k}^{\prime}$.

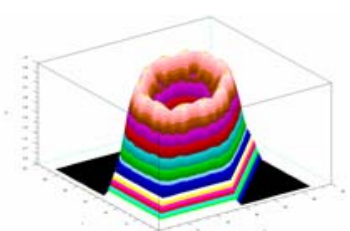

(a)

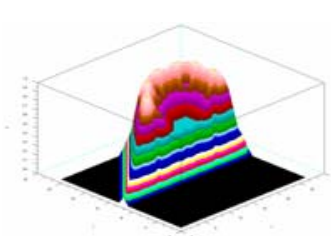

(b)
Figure 3. Normalized neutron flux of base case calculation; (a) full core (b) half core

From Figure 3, higher enrichment in the outer core region results in increasing neutron flux in the region. On the other hand, lower inner core height also causes the depletion of inner core flux due to larger amount of axial neutron leakage. This configuration gives the radial peaking factor of 1.34 . 


\subsection{Case 1: Inclusion of MAs of $2.26 \%$ of Pu}

Minor Actinides (MAs), such as $\mathrm{Np}^{237}, \mathrm{Am}^{241}$, $\mathrm{Am}^{243}$ and $\mathrm{Cm}^{244}$, tends to induce positive reactivity into the core. Like many other fission products, the accumulation of MAs increases as burn up increases. In this calculation, MAs of $2.26 \%$ of Pu contents is chosen that comprises of $59 \% \mathrm{~Np}^{237}, 29 \% \mathrm{Am}^{241}$, 9.5\% $\mathrm{Am}^{243}$ and $2.5 \% \mathrm{Cm}^{244}$.

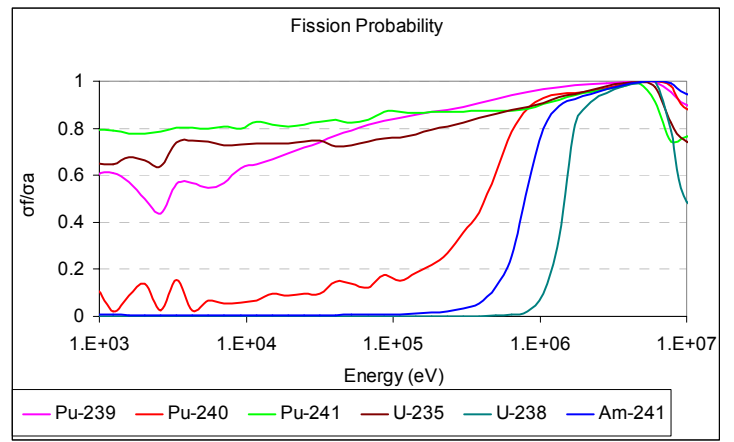

Figure 4. Fission probability of important isotopes in FBR

The calculation shows that the void reactivity due to the inclusion of MAs is $1.254 \% \Delta \mathrm{k} / \mathrm{k}^{\prime}$, meaning that the existence of MAs induces $+0.044 \% \Delta \mathrm{k} / \mathrm{k}^{\prime}$ compared to base case result.

During the voiding process, the neutron spectrum hardens to higher energy spectrum due to losing neutron slowing down from the coolant. As Figure 4 shows, the fission probability of MAs, represented by $\mathrm{Am}^{241}$ in the figure, drastically jumps up leading to higher fission reaction in the core. The similar characteristics are also exhibited by fissionable isotopes such as $\mathrm{U}^{238}$ and $\mathrm{Pu}^{240}$.

\subsection{Case 2: Uniform inner and outer core height}

Unlike the base case core, in this calculation the inner and outer core regions are loaded with the fuels having the same height, while the enrichment is the same as the base case core.

Both excess reactivity as well as void reactivity increases significantly from the base case calculation. The increase in excess reactivity is understandably caused by the increase in the amount of fissile material in the inner core due to height increase, while the increase in void reactivity is particularly due to the reduction of neutron leakage in the axial direction during voided condition. In this case, the void reactivity reaches $1.600 \% \Delta \mathrm{k} / \mathrm{k}^{\prime}$. It means uniform inner and outer core height gives effect on void reactivity of $+0.391 \% \Delta \mathrm{k} / \mathrm{k}^{\prime}$ compared to the base case.

Compared to the base case neutron flux distribution, the flux in the inner core region slightly increases to the similar level as outer core region. Such neutron flux distribution favorably reduces the radial peaking factor into 1.26 from 1.34 of the base case.

\subsection{Case 3: Heterogeneous core configuration}

Heterogeneous core configuration is a configuration where the inner and / or outer core regions are loaded not only with driver assemblies but also blanket assemblies. Heterogeneous core configuration reduces excess reactivity as a result of reduction in fissile material in the inner and / or outer core region. Therefore, this configuration can be employed for the initial core configuration where the core is fully loaded with fresh fuels in order to reduce excess reactivity finally increase the shutdown margin.

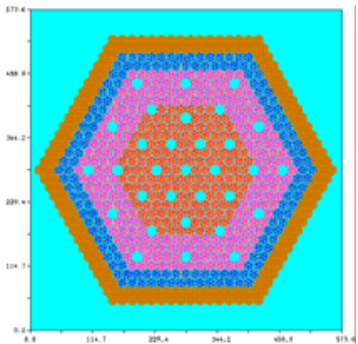

(a)

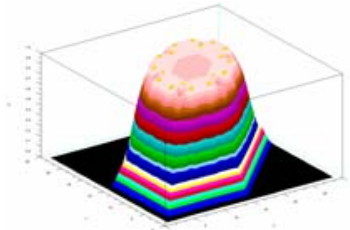

(c)

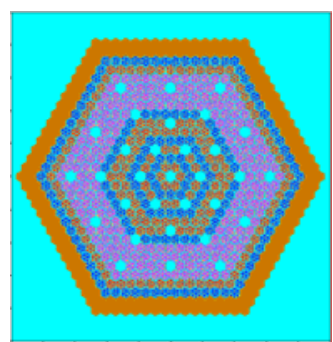

(b)

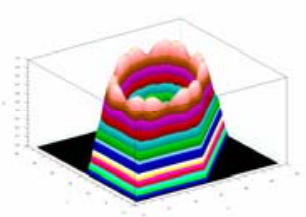

(d)
Figure 5. (a) Homogeneous configuration, (b) Heterogeneous configuration, (c) normalized neutron flux distribution of homogeneous configuration, (d) normalized neutron flux distribution of heterogeneous configuration

In this calculation, the inner and outer core regions are loaded with fuels having the same height in order to avoid the effect of different fuel height. Heterogeneous configuration is arranged by interchanging the same number of fuel assemblies in the inner core region with the blanket assemblies in such a way that the number fuel drivers and blanket assemblies are the same as those in the homogeneous configuration. The result of this calculation is then compared to the case 2. Figure 5 shows both homogeneous and heterogeneous core configuration, and their respective normalized neutron flux distributions.

The calculation result shows that the excess reactivity significantly decreases from 6.545 to 1.995 $\% \Delta \mathrm{k} / \mathrm{k}$. Similarly, the void reactivity decreases from 1.600 to $0.830 \% \Delta \mathrm{k} / \mathrm{k}^{\prime}$, therefore the effect of heterogeneous configuration is reducing the void reactivity by $0.771 \% \Delta \mathrm{k} / \mathrm{k}^{\prime}$. 
As it is seen from Figure 5, there is steep decrease of neutron flux in the inner core region that consequently results in significant increase of radial peaking factor from 1.26 to 1.71 .

\subsection{Case 4: Elimination of upper plenum}

This evaluation is intended to observe the effect of upper plenum to the void reactivity which is filled with void. The void reactivity in this case reaches $1.094 \% \Delta \mathrm{k} / \mathrm{k}^{\prime}$. Thus, the elimination of upper plenum reduces void reactivity by $0.115 \% \Delta \mathrm{k} / \mathrm{k}^{\prime}$. In other word, the installation of upper plenum increases the void reactivity, because it reduces the change of neutron leakage from flooded to voided condition in the axial direction due to the reduction of coolant volume above the core.

\subsection{Case 5: The effect $85 \mathrm{~cm}$ upper plenum}

In this case, the upper and lower plenums are interchanged from the base case, so it has $85 \mathrm{~cm}$ of upper plenum and $15 \mathrm{~cm}$ of lower plenum. This results in void reactivity of $1.256 \% \Delta \mathrm{k} / \mathrm{k}^{\prime}$, or it is up 0.047 $\% \Delta \mathrm{k} / \mathrm{k}^{\prime}$ from the base case. This result is also consistent with Case 4.

\subsection{Case 6: Shorter upper blanket $(15 \mathrm{~cm})$}

In Case 6, the upper blanket is reduced from 30 $\mathrm{cm}$ of the base case to $15 \mathrm{~cm}$, to see the effect of upper blanket to the void reactivity. The void reactivity becomes $1.029 \% \Delta \mathrm{k} / \mathrm{k}^{\prime}$ that means $0.180 \% \Delta \mathrm{k} / \mathrm{k}^{\prime}$ lower than the base case. The decrease of void reactivity is clearly caused by increasing neutron leakage in the axial direction.

\subsection{Case 7: Voiding in the inner core}

In this study, the voiding is assumed to occur in the inner core region only, meanwhile the outer core region remains in flooded condition. This evaluation together with Case 8 is aimed at observing the sensitivity of voiding in the radial space to the void reactivity and the effect of radial neutron leakage. The calculation shows that voiding in the inner core induces positive reactivity of $0.622 \% \Delta \mathrm{k} / \mathrm{k}^{\prime}$. Since the inner core region is loaded with 150 fuel assemblies, voiding in one fuel assembly roughly increases the reactivity by $4.145 \times 10^{-3} \% \Delta \mathrm{k} / \mathrm{k}^{\prime}$.

\subsection{Case 8: Voiding in the outer core}

Unlike Case 7, in this calculation the voiding is assumed to take place in the outer core region, while the inner core region remains flooded. The result indicates that voiding in the outer core region increases reactivity by $0.630 \% \Delta \mathrm{k} / \mathrm{k}^{\prime}$. This region is occupied by 216 fuel assemblies. Therefore, one fuel assembly induces $+2.917 \times 10^{-3} \% \Delta \mathrm{k} / \mathrm{k}^{\prime}$ in average.

Compared to the Case 7 , the positive reactivity induction per fuel assembly in the outer core region is lower than that of in the inner core region, even though the neutron flux in the outer core region is higher. This fact clearly implies that radial neutron leakage in the outer core region during voiding is higher than that of in the inner core region, since the outer core region is located closer to the peripheral region. On the other hand during voiding in the inner core region, the radial neutron leakage is isolated by outer core region which remains flooded.

If we sum up the result of Case 7 and Case 8, the void reactivity is close to the base case calculation, but not exactly the same, because each case is not independent.

\subsection{Case 9: The effect of pin pitch}

In this analysis, the change of $\mathrm{P} / \mathrm{D}$ is done by changing the fuel pin pitch while the fuel pin diameter remains the same. The pitch size is expanded in both sides, narrower and wider than the base case pitch. The change of fuel pitch will consequently change the fuel assembly size and total core width $(W)$. And most importantly, it changes the volume fraction between fuel, coolant and structural material in the core region. Figure 6 describes the influence of fuel pitch to both excess reactivity and void reactivity.

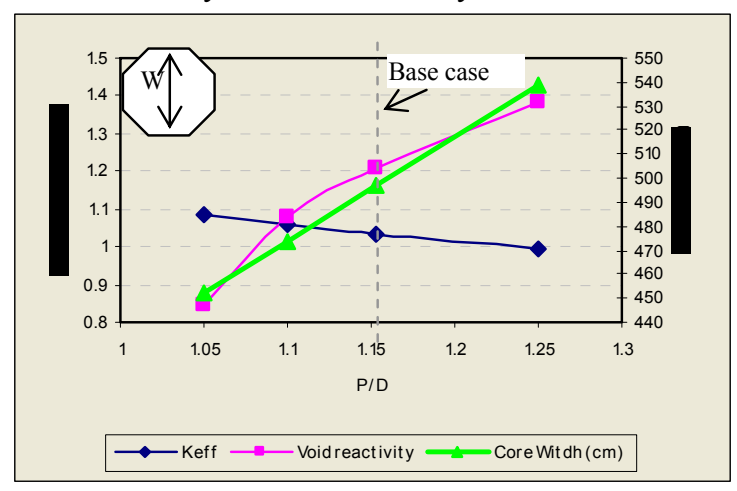

Figure 6. The effect of pin pitch to $\mathrm{K}_{\mathrm{eff}}$ and void reactivity

From Figure 6, reducing the fuel pitch will result in the decrease of void reactivity and increase in $\mathrm{K}_{\text {eff. }}$ Both changes are favorable in term of safety and neutron economic performance, but it addresses thermal hydraulic constraint. Reducing the fuel pitch means raising the fuel volume fraction and decreasing the coolant one. Raising the fuel volume fraction leads to increasing the excess reactivity, while at the same time reduces the volume of coolant to be voided that consequently limits the neutron spectrum hardening.

\subsection{Void Reactivity Profile}

To draw the void reactivity profile versus void fraction, several calculations are performed from $0 \%$ to $100 \%$ of void fraction (completely voided) for the base case core configuration. Void fraction steps of $10 \%$ are chosen. 


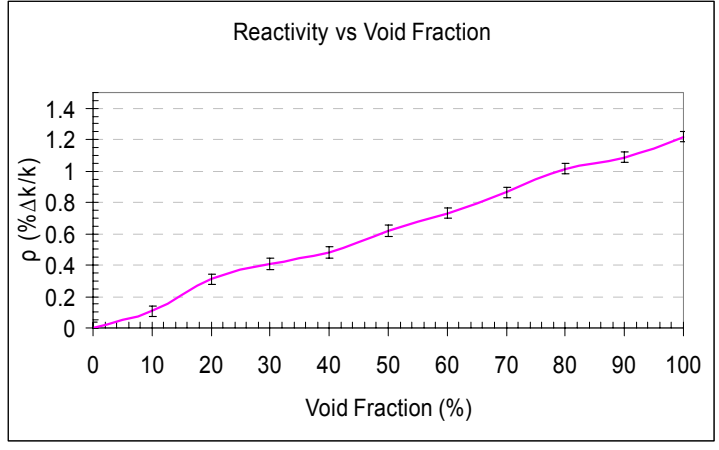

Figure 7. Void reactivity vs void fraction
Figure 7 shows that the void reactivity increases linearly as the void fraction increases. Thus, for conservative safety analysis it is recommended to assume $100 \%$ voiding or completely voided, since it addresses the maximum positive void reactivity.

The calculation result of the above cases is summarized in Table2

Table 2. Summary of the calculation results

\begin{tabular}{|c|c|c|c|c|c|c|c|}
\hline \multirow{2}{*}{ Case } & \multirow{2}{*}{ Parameter } & \multicolumn{2}{|c|}{ Flooded Condition } & \multicolumn{2}{|c|}{ Voided Condition } & \multirow{2}{*}{$\begin{array}{c}\text { Void } \\
\text { reactivity } \\
\left(\% \Delta k / k^{\prime}\right) \\
\end{array}$} & \multirow{2}{*}{$\begin{array}{c}\text { Effect on Void } \\
\text { Reactivity } \\
\left(\% \Delta \mathrm{k} / \mathbf{k}^{\prime}\right) \\
\end{array}$} \\
\hline & & Keff & Std. Dev & Keff & Std.Dev & & \\
\hline & Base case core & 1.03549 & $0.0121 \%$ & 1.04862 & $0.0126 \%$ & 1.209 & \\
\hline 1 & MAs Inclusion of $2.26 \%$ of $\mathrm{Pu}$ & 1.02947 & $0.0128 \%$ & 1.04293 & $0.0128 \%$ & 1.254 & 0.044 \\
\hline 2 & Uniform inner \& outer core height & 1.07003 & $0.0117 \%$ & 1.08867 & $0.0122 \%$ & 1.600 & 0.391 \\
\hline 3 & Heterogeneous core configuration & 1.02036 & $0.0127 \%$ & 1.02907 & $0.0127 \%$ & 0.830 & $-0.771 *$ \\
\hline 4 & Elimination of upper plenum & 1.03549 & $0.0124 \%$ & 1.04736 & $0.0134 \%$ & 1.094 & -0.115 \\
\hline 5 & Effect of $85 \mathrm{~cm}$ upper plenum & 1.03483 & $0.0126 \%$ & 1.04846 & $0.0130 \%$ & 1.256 & 0.047 \\
\hline 6 & Shorter upper blanket $(15 \mathrm{~cm})$ & 1.03745 & $0.0129 \%$ & 1.04865 & $0.0124 \%$ & 1.029 & -0.180 \\
\hline 7 & Voiding in inner core & 1.03549 & $0.0121 \%$ & 1.04220 & $0.0130 \%$ & 0.622 & \\
\hline 8 & Voiding in outer core & 1.03549 & $0.0121 \%$ & 1.04229 & $0.0130 \%$ & 0.630 & \\
\hline
\end{tabular}

* compared to Case 2 .

\section{Conclusions}

Several parameters have been verified to confirm their effect on void reactivity. Such parameters then could be taken into account during LMFBR core design to optimize both safety and economic performance.

Parameters that induce positive void reactivity are the accumulation of minor actinides, increase in the core height, installation of upper plenum and higher coolant volume fraction.

While heterogeneous core configuration; reduction of upper blanket; and higher fuel volume fraction (lower coolant fraction) decrease the void reactivity.

\section{References}

1. H. Ninokata, Y. Hizume, H. Endo, and T. Sawada., Evaluation of Self-controllability of LMFRs against ATWS, Progress in Nuclear Energy, Vol. 40, No. 3-4, pp.569-575, 2002.

2. T. Yokoyama and N. Ueda, An Optimization Study on the Reflector-controlled Long Life LMR Core Aiming at a Negative Sodium Void Reactivity, $11^{\text {th }}$ International Conference on Nuclear Engineering (ICONE11-36284), Tokyo, Japan, April 20-23, 2003.

3. K. Tucek, J. Wallenius and W. Gudowski, Coolant Void Worth in Fast Breeder Reactors and Accelerator-driven Transuranium and Minoractinide Burners, Technical note, Annals of Nuclear Energy, 31, 1783-1801, 2004. 